\title{
Statistical Analysis of the Effect of Nanoparticles Volume Fraction on Turbulent Forced Convective Heat Transfer Coefficient of Nanofluid in a Circular Tube
}

\author{
Farhad Vahidinia ${ }^{1,}$, , Behrooz Keshtegar ${ }^{2}$, Mohadeseh Miri ${ }^{3}$ \\ ${ }^{1}$ Department of Mechanical Engineering, University of Zabol, Zabol, Iran \\ 2Department of Civil Engineering, University of Zabol, Zabol, Iran \\ ${ }^{3}$ Department of Mechanical Engineering, University of Zabol, Zabol, Iran \\ *Corresponding Author: Farhad Vahidinia, P.O.B. 9861335856, Phone: +989155440691, e-mail: f.vahidinia@gmail.com
}

\begin{abstract}
In this paper, the statistical analysis of the effect of nanoparticles volume fraction on one of the most important thermal characteristics turbulent flow of nanofluid i.e. convection heat transfer coefficient, inside a circular tube with uniform wall heat flux is investigated numerically. Also, water as a base fluid and $\mathrm{Al}_{2} \mathrm{O}_{3}$ as suspended particles with a diameter of $36 \mathrm{~nm}$ are considered. Heat transfer characteristics are computed using the solution of elliptic equations based on discrete the finite volume method and the second order upwind. The relationship between pressure and velocity using SIMPLEC algorithm is established. In this study, the variation of volume fraction of nanoparticles is assumed in the range of 0 to $6 \%$. The best probability distribution function of the heat transfer parameters are selected using chi square test that various probability distribution such as: Gamma, Normal, Lognormal, Gumbel, and Frechet are evaluated based on numerical analysis of tube flow. After reviewing the results, it was found that with increasing volume fraction of nanoparticles, the convective heat transfer coefficient increases. On the other hand, the convective heat transfer coefficients with regard to variation of volume fraction of nanoparticles follow Gumbel Max probability distribution function.
\end{abstract}




\section{Introduction}

$\mathrm{T}$ he convective heat transfer coefficient is one of the most important thermal parameters of fluid. So far, different methods in order to increase the heat transfer have been proposed, that the method of adding metal and nonmetal particles in different sizes, especially in nanometer scale to base fluid was highly regarded [1-3]. Researchers have studied the nanofluid issue both of experimentally and numerically method [4-5]. Minea [6] studied turbulent convective heat transfer in a twodimensional micro tube numerically. She used from water- $\mathrm{Al}_{2} \mathrm{O}_{3}$ nanofluids with different volume fractions ranged from $1 \%$ to $4 \%$ and showed that convective heat transfer coefficient of nanofluid is greater than of the base fluid. Farajollahi et al [7] investigated turbulent heat transfer of nanofluids in a shell and tube heat exchanger experimentally. They concluded that with adding of nanoparticles to the base fluid, the characteristics of heat transfer enhance remarkably. Dawood et al [8] laminar mixed convective heat transfer of different nanofluids in an elliptic annulus investigated numerically. They showed that the Nusselt number increased as the nanoparticle volume fraction increased. Saha and Paul [9] numerically examined the turbulent forced convection using $\mathrm{Al}_{2} \mathrm{O}_{3}$-water and $\mathrm{TiO}_{2}$-water nanofluids in a horizontal circular tube. They showed that $\mathrm{TiO}_{2}$-water nanofluid is the most energy efficient coolant than $\mathrm{Al}_{2} \mathrm{O}_{3}$-water nanofluid. Kaminski and Ossowski [10] predicted of the effective parameters of the nanofluids using the generalized stochastic perturbation method. They used of probabilistic and statistical methods for numerical determination of the effective physical properties of nanofluids. There's Computational experiments showed a very good agreement of the probabilistic characteristics computed using analytical, perturbation and simulation methods. Bianco et al [11] studied of turbulent convection heat transfer of nanofluid in circular tubes by using the mixture model. They resulted that with increasing of nanoparticles volume fraction, the
Nusselt number increases. Khanafer and Vafai [12] investigated of critical combination of thermophysical characteristics of nanofluids. They realized that experimental results for the effective thermal conductivity and viscosity reported by various authors are in disagreement. They presented correlations for effective thermal conductivity and viscosity of nanofluids. Corcione [13] presented a semi-empirical model for predicting the effective dynamic viscosity of nanofluids. His equation is accurate for both numerical simulation purposes and thermal design. Kamyar et al [14] studied application of computational fluid dynamics for nanofluids. They review and summarize the numerical studies performed in this area including conventional numerical methods as well as the new Lattice Boltzmann. They found that many of these computational simulations are in good agreement with experimental results. Tahir and Mital [15] investigated numerically laminar forced convective heat transfer in developing flow for water/aluminum oxide nanofluid in a circular channel under uniform heat flux on the wall. They investigated effect of three independent variables (particle diameter, the Reynolds number and volume fraction of nanoparticles) on the convective heat transfer coefficient. They predicted that in terms of effectiveness, the most significant variable is Reynolds number and volume fraction of nanoparticles is the least important variable.

In this paper, useful the probability distribution functions such as Gamma Normal, log-normal, Gumbel, and Frechet are evaluated for the turbulent forced convective heat transfer coefficient of water $/ \mathrm{Al}_{2} \mathrm{O}_{3}$ nanofluid, based on variation of nanoparticles volume fraction are investigated in a circular copper tube under heat flux at the top of tube and insulation in bottom. The maximum likelihood method is used to determine the parameters of the probability distribution functions. The best distribution function is chosen using Chi-square test. The parameters of the distribution function and statistical characteristics such as the first moment (Mean), the second moment (Standard Deviation), the third moment (Skewness), and 
fourth moments (Kurtosis) are compared in both the developed region and the developing region of nanofluid flow.

\section{The Flow Modeling}

A tube with circular cross section of copper is considered to evaluate the statistical analysis of turbulent flow convection heat transfer which the pipe geometric and boundary condition in Fig. 1. The length of pipe is 1000 millimeters, the inner and outer radius are 10 and 11 millimeters, respectively. Upper half tube with heat flux $42 \times 10^{4} \mathrm{~W} / \mathrm{m}^{2}$ and the bottom half of the tube is insulation. Turbulent flow of water- $\mathrm{Al}_{2} \mathrm{O}_{3}$ nanofluid is considered with different volume fractions ranged from 0 to $6 \%$ and inlet temperature of $293 \mathrm{~K}$ and inlet velocity of $\mathrm{V}_{\text {o. }}$.

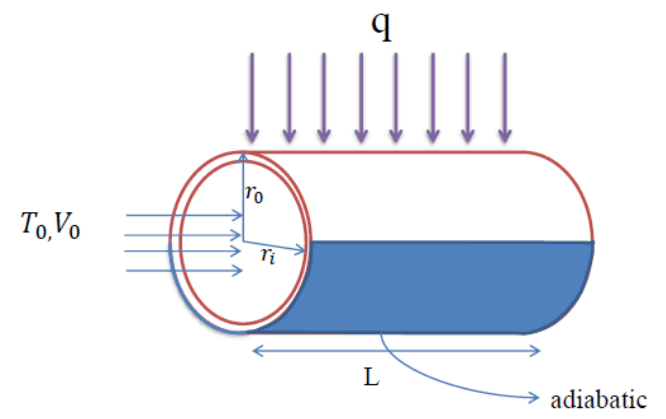

Figure 1: Schematic geometric of tube

\subsection{Governing Equations}

The two phase mixture model for pipe flow analysis and calculation of heat transfer characteristics are used that the governing equations described as follows:

\subsubsection{Continuity equation}

Continuity equation for a multi-phase flow is given by the following expression [16]:

$$
\nabla \cdot\left(\rho_{\text {eff }} V_{\mathrm{m}}\right)=0
$$

Where $V_{m}$ is mean axial velocity and $\mathrm{Qm}_{\mathrm{m}}$ is mixture of density which is defined as follows [17]:

$\mathbf{V}_{\mathrm{m}}=\frac{\sum_{k=1}^{n} \phi_{\mathrm{k}} \rho_{\mathrm{k}} \mathbf{V}_{\mathrm{k}}}{\rho_{\mathrm{m}}}$

$\rho_{\mathrm{m}}=\sum_{k=1}^{n} \phi_{k} \rho_{\mathrm{k}}$
Where $\phi_{\mathrm{k}}$ is the volume fraction of phase $\mathrm{k}$ and $\mathrm{V}_{\mathrm{k}}$ is mean axial velocity of phase $\mathrm{k}$ and $\varrho \mathrm{k}$ is density of phase $\mathrm{k}$.

\subsubsection{Momentum equation}

Momentum equation of multi-phase flow in a pipe is as follows [16]:

$\nabla \cdot\left(\rho_{\mathrm{m}} \mathbf{V}_{\mathrm{m}} \mathbf{V}_{\mathrm{m}}\right)=-\nabla \mathbf{P}_{\mathrm{m}}+\nabla \cdot\left(\tau-\tau_{\mathrm{t}}\right)+\nabla \cdot\left(\sum_{\mathrm{k}=1}^{\mathrm{n}} \phi_{\mathrm{k}} \rho_{\mathrm{k}} \mathbf{V}_{\mathrm{dr}, \mathrm{k}} \mathbf{V}_{\mathrm{dr}, \mathrm{k}}\right)$

In the above equation, $\mathrm{n}$ is the number of phases, and $\mathrm{P}$ is the pressure of the mixture. $\mathrm{V}_{\mathrm{dr}, \mathrm{k}}$ is the rate leads for phase of $\mathrm{k}$ which defined as [16]:

$\mathbf{V}_{\mathrm{dr}, \mathrm{k}}=\mathbf{V}_{\mathrm{k}}-\mathbf{V}_{\mathrm{m}}$

In the Eq (4), $\tau$ and $\tau_{t}$ are the shear stress and turbulent shear stress, respectively. They are calculated by the following relations.

$\tau=\mu_{\text {eff }} \nabla \mathbf{V}_{\mathrm{m}}$

$\tau_{t}=\sum_{k=1}^{n} \phi_{k} \rho_{k} \overline{v_{k} v_{k}}$

Where $\mu_{\text {eff }}$ is effective viscosity of nanofluids, which is depended on the physical properties of nanofluids.

The relative velocity $\left(\mathrm{V}_{\mathrm{pf}}\right)$ is defined based on the relative speed of the second phase (particles, $\mathrm{p}$ ) in the first phase (base fluid, f) as follows [11]: $\mathbf{V}_{\mathrm{pf}}=\mathbf{V}_{\mathrm{p}}-\mathbf{V}_{\mathrm{f}}$

Based on $\mathrm{Eq}(8)$, relationship between the slip velocity an drift velocity is defined as [11]:

$\mathbf{V}_{\mathrm{dr}, \mathrm{p}}=\mathbf{V}_{\mathrm{pf}}-\sum_{\mathrm{k}=1}^{n} \frac{\phi_{\mathrm{k}} \rho_{\mathrm{k}}}{\rho_{\mathrm{m}}} \mathbf{V}_{\mathrm{fk}}$

The relative velocity between the two phases is calculated by Mannien relation [18].

$\mathbf{V}_{\mathrm{pf}}=\frac{\rho_{\mathrm{p}} \mathrm{d}_{\mathrm{p}}^{2}}{18 \mu_{\mathrm{f}} \mathrm{f}_{\text {drag }}} \frac{\left(\rho_{\mathrm{p}}-\rho_{\mathrm{m}}\right)}{\rho_{\mathrm{p}}} \mathrm{a}$

Where $Q_{p}$ is nanoparticle density, $d_{p}$ is diameter of the nanoparticles and $\mu_{\mathrm{f}}$ is the fluid viscosity (water) and $f_{d r a g}$ is drag function that are calculated as follows [19]:

$\mathrm{f}_{\text {drag }}=\left\{\begin{array}{ccc}1+0.15 \operatorname{Re}_{\mathrm{p}}^{0.687}, & \operatorname{Re}_{\mathrm{p}} \leq 1000 \\ 0.0183 \operatorname{Re}_{\mathrm{p}} \quad, & \operatorname{Re}_{\mathrm{p}}>1000\end{array}\right\}$

The acceleration (a) in Eq. (10) and $\operatorname{Re}_{\mathrm{p}}$ in Eq (11) are defined as:

$\mathrm{a}=\mathrm{g}-\left(\mathbf{V}_{\mathrm{m}} \cdot \nabla\right) \mathbf{V}_{\mathrm{m}}$

$\mathrm{Re}_{\mathrm{nf}}=\frac{\mathrm{V}_{\mathrm{nf}} \mathrm{D}}{\mathrm{v}_{\mathrm{nf}}}$

In which, $\mathrm{D}$ is the pipe diameter, $\mathrm{V}_{\mathrm{nf}}$ is speed nanofluids, $v_{\text {nf }}$ is kinematic viscosity of 
nanofluids and $\mathrm{g}$ is the acceleration of gravity $\left(9.807 \mathrm{~m} / \mathrm{s}^{2}\right)$.

\subsubsection{The energy equation}

The energy equation is solved for a multiphase turbulent flow which is defined as follows [16]:

$$
\nabla \cdot\left(\sum_{k=1}^{n} \phi_{k} V_{k}\left(\rho_{k} H_{k}+P\right)\right)=\nabla \cdot\left(\lambda \nabla T-C_{p} \rho_{m} \overline{v t}\right)
$$

Where $H_{k}$ is enthalpy of $k_{t h}$ phase, $P$ is the pressure, $\mathrm{T}$ is the temperature, $\mathrm{C}_{\mathrm{p}}$ is specific heat capacity, $v$ is rapidly oscillating and $\mathrm{t}$ is perturbations of the parameter. Turbulent flow is modelled based on $k-\varepsilon$ equation [20].

\subsection{Physical properties of nanofluids}

The effective density of nanofluids is calculated by following equation [21].

$$
\rho_{\text {eff }}=(1-\phi) \rho_{\mathrm{f}}+\phi \rho_{\mathrm{p}}
$$

Where $\varphi$ is the volume fraction of nanoparticles and specific heat capacity of nanofluids in Eq. (14) can be calculated as [21]:

$$
\left(C_{p}\right)_{\text {eff }}=\left[\frac{(1-\phi)\left(\rho C_{p}\right)_{f}+\phi\left(\rho C_{p}\right)_{p}}{(1-\phi) \rho_{\mathrm{f}}+\phi \rho_{p}}\right]
$$

Where $(C p)_{f}$ and $(C p)_{p}$ are the specific heat capacity of the fluid (water) and nanoparticle (aluminum oxide) respectively. Effective thermal conductivity Eq. (14) is considered as [22].

$$
\begin{aligned}
& \frac{\lambda_{\text {eff }}}{\lambda_{f}}=1+64.7 * \phi^{0.746}\left(\frac{d_{f}}{d_{p}}\right)^{0.369} \\
& *\left(\frac{\lambda_{p}}{\lambda_{f}}\right)^{0.746} * \operatorname{Pr}^{0.9955} * \operatorname{Re}^{1.2321}
\end{aligned}
$$

Where $d_{f}$ and $d_{p}$ are the particle diameter base fluid $(0.275 \mathrm{~nm})$ and the diameter of the nanoparticles (36 nm) respectively. $\lambda_{\mathrm{f}}$ and $\lambda_{\mathrm{p}}$ are named the fluid conductivity (0.6028 w/m k) and the conductivity of nanoparticles ( $35 \mathrm{w} / \mathrm{m} \mathrm{k}$ ), respectively. Dimensionless parameters such as $\operatorname{Pr}$ (Prandtl number) and Re (Reynolds number) in Eq (17) are defined as follows:

$$
\begin{aligned}
& \operatorname{Pr}=\frac{\mu_{\mathrm{f}}}{\rho_{\mathrm{f}} \alpha_{\mathrm{f}}} \\
& \operatorname{Re}=\frac{\rho_{\mathrm{f}} \mathrm{K}_{\mathrm{b}} \mathrm{T}}{3 \pi \mu^{2} \mathrm{~L}_{\mathrm{bf}}}
\end{aligned}
$$

In which Lbf $(\mathrm{m})$ is called over the free path and its value for water at laboratory temperature $\left(25^{\circ} \mathrm{C}\right)$ is equal to $(0.17 \mathrm{~nm}) . \mathrm{K}_{\mathrm{b}}$ is Boltzmann constant $\left(\mathrm{K}_{\mathrm{b}}=1.3807 \times 10^{-23}(\mathrm{~J} / \mathrm{K})\right)[22], \mu$ is the fluid viscosity which is defined as:

$\mu_{\mathrm{f}}=\mathrm{A} \times 10^{\frac{\mathrm{B}}{\mathrm{T}-\mathrm{C}}}$

Where the constants of $\mathrm{A}=2.414 \times 10^{-5}$ (Pa.s),$\cdot \mathrm{B}=247\left({ }^{\circ} \mathrm{K}\right)$ and $\mathrm{C}=140\left({ }^{\circ} \mathrm{K}\right)$

The effective viscosity of the nanofluid ( $\left.\mu_{\text {eff }}\right)$ in Eq (6) is depended on temperature (T), the average diameter of the nanoparticles $d_{p}$, nanoparticle volume fraction $(\phi)$, nanoparticle density $Q_{p}$ and the physical properties of base fluid. $\mu_{\text {eff }}$ is calculated by following relation [23]:

$\mu_{\text {eff }}=\mu_{\mathrm{f}}+\frac{\rho_{\mathrm{P}} \mathrm{V}_{\mathrm{B}} \mathrm{d}_{\mathrm{P}}^{2}}{72 \mathrm{C} \delta}$

In which $V_{B}$ is Brownian velocity and $\delta$ is boundary layer thickness which are obtained as [23].

$\mathrm{V}_{\mathrm{B}}=\frac{1}{\mathrm{~d}_{\mathrm{P}}} \sqrt{\frac{18 \mathrm{~K}_{\mathrm{b}} \mathrm{T}}{\pi \rho_{\mathrm{P}} \mathrm{d}_{\mathrm{P}}}}$

$\delta=\sqrt[3]{\frac{\pi}{6 \phi}} \mathrm{d}_{\mathrm{P}}$

$\mathrm{C}=\mu_{\mathrm{f}}^{-1}\left[\left(\mathrm{c}_{1} \mathrm{~d}_{\mathrm{p}}+\mathrm{c}_{2}\right) \phi+\left(\mathrm{c}_{3} \mathrm{~d}_{\mathrm{p}}+\mathrm{c}_{4}\right)\right]$

Where:

$c_{1}=-0.000001133, c_{2}=-0.000002771$

$c_{3}=0.00000009, c_{4}=-0.000000393$

\section{Numerical solution}

In this paper, heat transfer characteristics are computed using the solution of elliptic equations based on discrete the finite volume method and the second order upwind. The relationship between pressure and velocity using SIMPLEC algorithm is established. This algorithm is more appropriate for incompressible flows into the tube [16]. The many of samples to generate data for the statistical properties of turbulent flow forced convection heat transfer of nanofluids parameters. The nanoparticles volume fraction is simulated in the range of 0 to $6 \%$. The results of convective heat transfer coefficient parameter to the nanoparticles volume fraction are shown in Figures 2 and 3. 


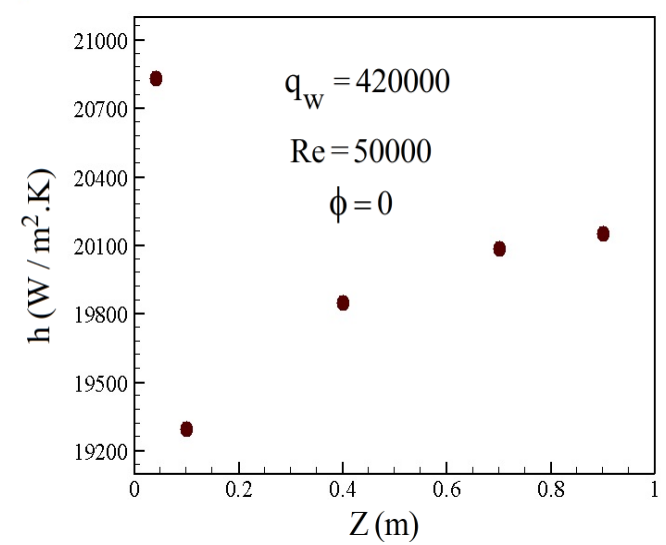

Figure 2: Convective heat transfer coefficient of base fluid in the tube length

In Figure 2, the convective heat transfer coefficient of turbulent flow for base fluid (water) is drawn along the tube length. As can be seen, the changes this parameter in the first part of the tube (developing region) is more intense than the end part of the tube (developed region). In Figure 3, the convective heat transfer coefficient is drawn in terms of volume fraction of nanoparticles ranging from 0.3 to 6 percent in different areas of tube length. As can be seen, with increasing volume fraction of nanoparticles the convective heat transfer coefficient increased which is due to thermo-physical properties of the fluid is improved.

\section{The method of statistical analysis}

The main of the present paper is the evaluation of statistical properties such as the probability distribution functions and their parameters for turbulent forced convective heat transfer coefficient variable with respect to the volume fraction of nanoparticles in the range of 0 to 6 percent. For this purpose, the parameters of probability distribution function based on maximum likelihood method and the probability distribution function is calculated based on the Chi-square test.

\section{1 estimating the parameters of the probability distribution function}

It is assumed that the random variable $X$ i.e. $h$, has a continuous probability density function $\mathrm{f}_{\mathrm{x}}(\mathrm{x})$. The probability distribution function has a number of unknown parameters. The calculation of the unknown parameters for a distribution function is main purpose for the variable $X$. The maximum likelihood method is used to determine the unknown parameters of PDF [24]. Therefore, the probability density distribution function $\mathrm{f}_{\mathrm{x}}(\mathrm{x})$ of the heat transfer data for observations is defined based on the maximum likelihood procedure as [25, 26]:

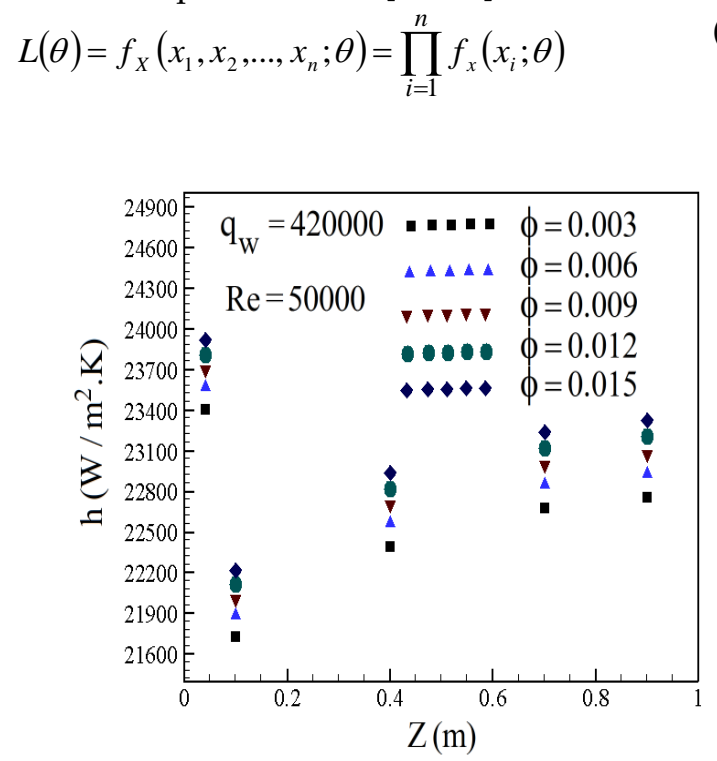

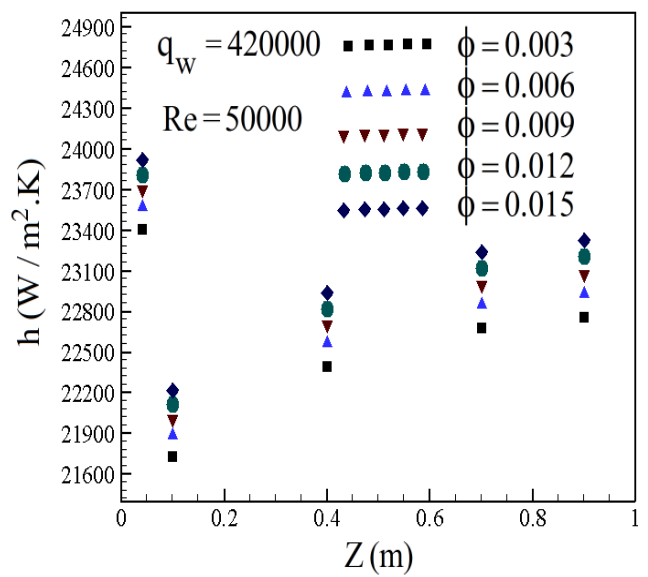

(a)

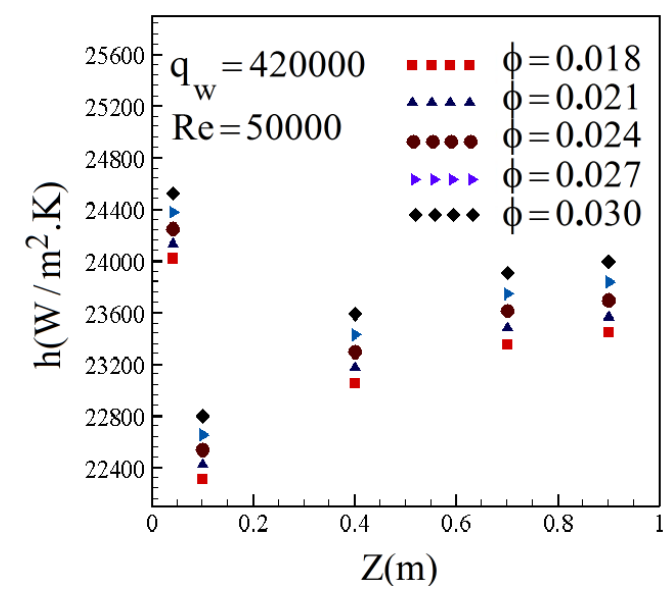

(b)

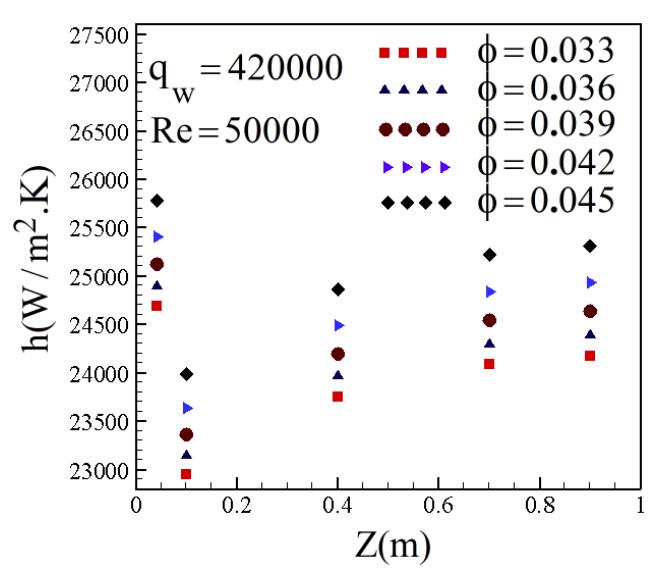


(c)

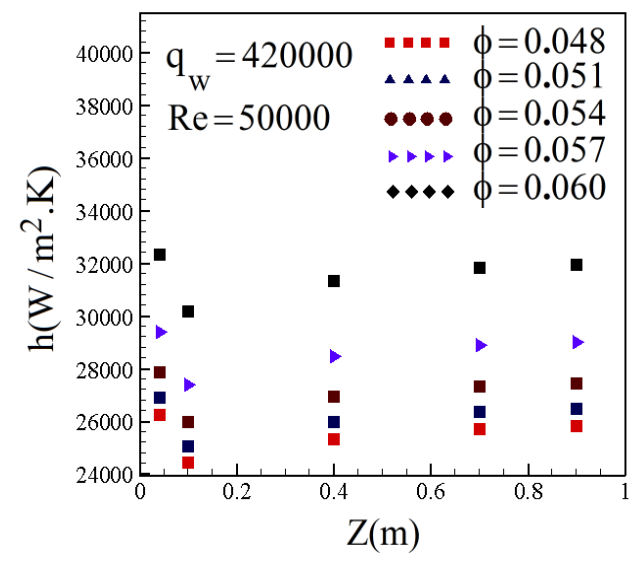

(d)

Figure 3: Convective heat transfer coefficient of nanofluid in the tube length for different volume fraction of nanoparticles

Where $L(\theta)$ is the likelihood of probability distribution function with the parameters $\theta$. The unknown parameters are calculated based on the maximization of Eq. (25). It is clear that equation is obtained for every parameter of probability distribution function. Solution of the equations is leaded to determine the unknown parameters of the probability density distribution function [25]. Consequently, we will have:

$\left[\frac{\partial L(\theta)}{\partial \theta_{1}}=0, \frac{\partial L(\theta)}{\partial \theta_{2}}=0, \ldots, \frac{\partial L(\theta)}{\partial \theta_{n}}=0\right]^{T}$

\subsection{Select the best distribution function}

The best probability distribution function which its parameters are calculated based on maximum likelihood estimator, is selected using chi- square statistic. Hence, the statistical data of the heat transfer are classified with $\mathrm{K}$ classes as [24]:

$\mathrm{K}=1+\log _{2} N$

Where $\mathrm{N}$ is the number of data and $\mathrm{K}$ is the number of classes. Chi-square value is calculated as follows:

$\chi^{2}=\frac{\sum_{\mathrm{i}=1}^{k}\left(\mathrm{O}_{\mathrm{i}}-\mathrm{E}_{\mathrm{i}}\right)^{2}}{\mathrm{E}_{\mathrm{i}}}$

In which, $\mathrm{O}_{\mathrm{i}}$ is the observed data based on numerical analysis and $E_{i}$ is defined for class $i_{\text {th }}$ as $F\left(x_{2}\right)-F\left(x_{1}\right)$. In which, $F$ is the cumulative distribution function for lower band $\left(\mathrm{x}_{1}\right)$ and upper band $\left(\mathrm{x}_{2}\right)$ of class. The minimum value of chi- square statistic shows that the data more confidence with the estimated data by PDF.

\section{Evaluation of the results of the}

\section{statistical analysis}

statistical properties of the heat transfer variables are evaluated based on the data generation from the numerical analysis of nanofluid in tube. The parameters of several PDFs are computed at various points along the tube which are located in flow developing and flow developed.

\section{1 statistical properties of heat transfer variables}

According to the results from numerical analysis of flow in tube, statistical properties of the heat transfer variables are approximated for 5 location of tube length. The statistical properties are included as

5.1.1 mean, which is calculated as follows [26]:

$\bar{X}=\frac{\sum_{i=1}^{n} x_{i}}{n}$

Where $\mathrm{n}=21$ and $X_{i}$ is the convective heat transfer coefficient values in developed and developing regions of the flow tube.

5.1.2 Standard deviation: It is calculated as follows [26]:

$S=\sqrt{\frac{\sum_{i=1}^{n}\left(x_{i}-\bar{x}\right)^{2}}{n-1}}$

5.1.3 The coefficient of variation: it is defined by the ratio of standard deviation to mean:

$\operatorname{Cov}=\frac{\mathrm{S}}{\overline{\mathrm{X}}}$

5.1.4 skewness: the deviation of the probability distribution function of data is shown with respected to the normal state which is tended to the right or left. It is calculated as follows:

$\mathrm{Sk}=\frac{\mathrm{n}}{(\mathrm{n}-1)(\mathrm{n}-2)} \sum_{\mathrm{i}=1}^{\mathrm{n}}\left(\frac{\mathrm{x}_{\mathrm{i}}-\overline{\mathrm{x}}}{\mathrm{S}}\right)^{3}$ 
If the value of skewness is equal to 3 , In this case the data follow a normal function. If the skewness is greater than 3 , the data probability distribution is tended to the left and the probability distribution function is tended to right when, skewness is smaller than 3 .

5.1.5 Kurtosis: it showed the steepness of the probability distribution function for the data with respected to the normal probability distribution function:

$$
\begin{aligned}
& K R=\left[\frac{n(n+1)}{(n-1)(n-2)(n-3)} \sum_{i=1}^{n}\left(\frac{X_{i}-\bar{X}}{S}\right)^{4}\right] \\
& -\frac{3(n-1)^{2}}{(n-2)(n-3)}
\end{aligned}
$$

If the kurtosis value is zero, the probability distribution function of the data is followed with the normal probability distribution function. It is sharper than normal probability distribution function when kurtosis is negative. When kurtosis is positive, the probability distribution function of data is smoother than the normal PDF.

Table 1: the statistical properties of convective heat transfer coefficient in different locations of tube

\begin{tabular}{cccccc}
\hline $\begin{array}{c}\text { Location of tube } \\
\text { (meter) }\end{array}$ & 0.04 & 0.1 & 0.4 & 0.7 & 0.9 \\
\hline $\begin{array}{c}\text { Mean } \\
\text { standard deviation }\end{array}$ & 25201 & 23435 & 24249 & 24582 & 24676 \\
coefficient of & 0.0955 & 0.0973 & 0.0997 & 0.1005 & 0.1007 \\
$\quad$ variation & 3.2525 & 3.2385 & 3.084 & 3.0474 & 3.0396 \\
$\quad$ Kurtosis & 1.4124 & 1.4089 & 1.3692 & 1.3598 & 1.3577 \\
Skewness & & & & & \\
\hline
\end{tabular}

According to statistical methods, the statistical properties of convective heat transfer coefficient parameter data is presented in Table 1. As seen in this table, the statistical properties of the convective heat transfer coefficient data are listed along five point of the tube (i.e. 0.04, $0.1,0.4,0.7$ and 0.9$)$ and compared. According to the results presented in Table 1 it is clear that the coefficient of variation in the range from 0.04 to 0.4 meters of the tube length are significant changes compared to the range from 0.4 to 9.0 meters of the tube length. By comparing the mean and standard deviation of data, the above results are also specified.

To investigate the kurtosis of data the probability distribution function for the data be should compared with the normal probability distribution function. As seen in this table, with regard to the kurtosis value of data is greater than zero, therefore the probability distribution function of data is smoother compared to normal probability distribution function. On the other hand, the probability distribution function of the convective heat transfer coefficient in the range from 0.04 to 0.1 is smoother than the range of 0.7 to 0.9 .

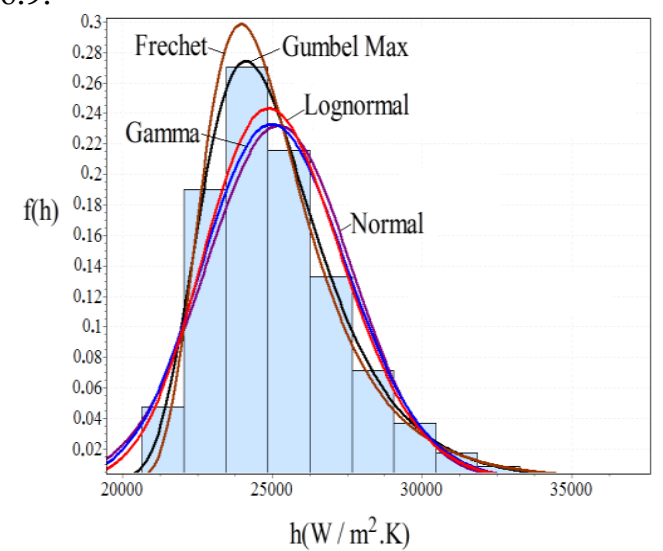

Figure 4: Appropriate probability distribution function of the convective heat transfer coefficient in $\mathrm{Z}=0.04$

The next issue that should be investigated, the statistical property is skewness. With regard to the skewness value of data shown in Table 1 is greater than 3 therefor, the data probability distribution function of the convective heat transfer coefficient in term of nanoparticles volume fraction is tended to the right. 


\subsection{Appropriate probability distribution of heat transfer variables}

The best probability distribution function of the convective heat transfer of turbulent flow heat transfer nanofluids is determined in a circular tube using chi-square tests. The best probability distribution function is selected from known functions including Gamma, Normal, Log-normal, Gumbel, and Frechet. This two-parameter probability distribution functions are defined as follows:

\subsubsection{Normal probability distribution function}

This probability distribution function for variable convective heat transfer coefficient is defined as follows:

$\mathrm{f}(\mathrm{h})=\exp \left[-\frac{1}{2}\left(\frac{\mathrm{h}-\mu}{\sigma}\right)^{2}\right] /(\mathrm{h}) \sigma \sqrt{2 \pi}$

In the above equation, $\mathrm{h}$ is the convective heat transfer coefficient. Also, $\sigma$ and $\mu$ are continuous scale parameter and continuous location parameter, respectively.

\subsubsection{Lognormal probability distribution}

\section{function}

This probability distribution function for variable convective heat transfer coefficient is defined as follows:

$$
\mathrm{f}(\mathrm{h})=\exp \left[-\frac{1}{2}\left(\frac{\ln (\mathrm{h})-\mu}{\sigma}\right)^{2}\right] /(\mathrm{h}) \sigma \sqrt{2 \pi}
$$

In this equation also, $\mathrm{h}$ is the convective heat transfer coefficient. Also, $\sigma$ and $\mu$ are continuous parameters.

\subsubsection{Gamma probability distribution function}

Gamma probability distribution function for variable convective heat transfer coefficient is expressed as follows:

$f(h)=(h)^{\alpha-1} \exp \left[-\left(\frac{h}{\beta}\right)\right] / \beta^{\alpha} \Gamma(\alpha)$

In the Eq (36), $\mathrm{h}$ is the convective heat transfer coefficient and $\alpha$ and $\beta$ are continuous shape parameter and continuous scale parameter, respectively.

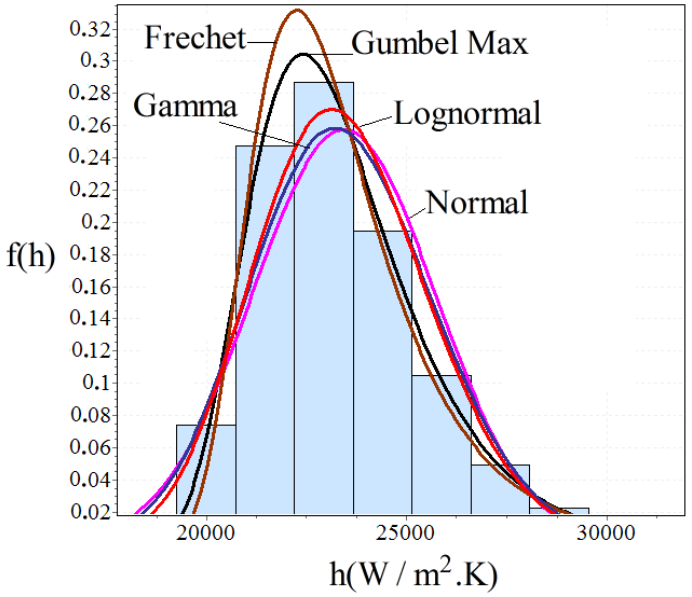

Figure 5: Appropriate probability distribution function of the convective heat transfer coefficient in $\mathrm{Z}=0.1$

\subsubsection{Frechet probability distribution function}

Frechet probability distribution function for variable convective heat transfer coefficient is expressed as follows:

$f(h)=\frac{\alpha}{\beta}\left(\frac{\beta}{h}\right)^{\alpha+1} \exp \left[-\left(\frac{\beta}{h}\right)^{\alpha}\right]$

In the $\mathrm{Eq}(37), \mathrm{h}$ is the convective heat transfer coefficient and $\alpha$ and $\beta$ are continuous shape parameter and continuous scale parameter, respectively.

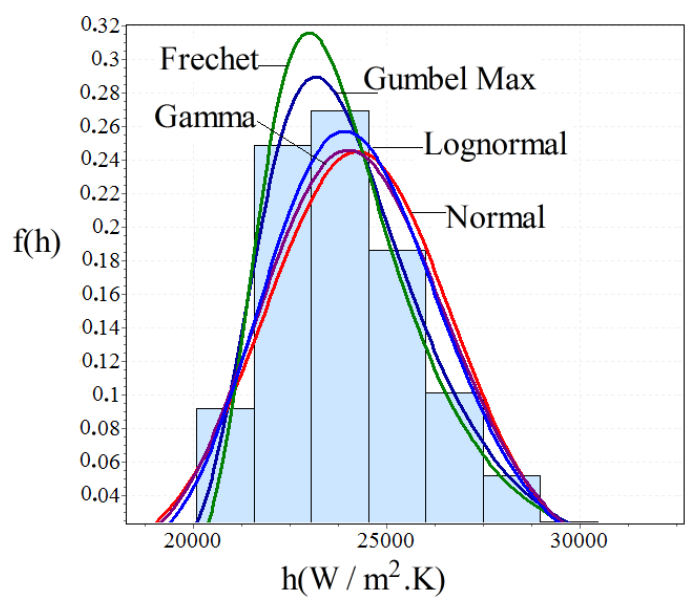

Figure 6: Appropriate probability distribution function of the convective heat transfer coefficient in $\mathrm{Z}=0.4$ 


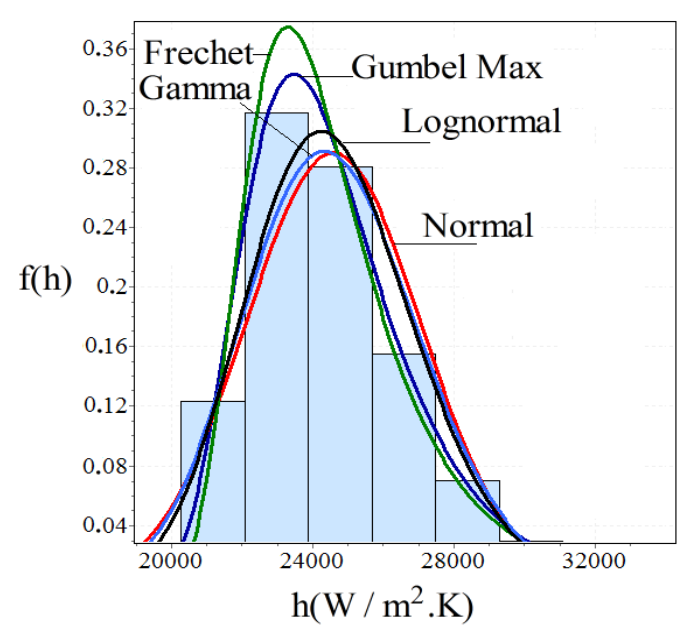

Figure 7: Appropriate probability distribution function of the convective heat transfer coefficient in $\mathrm{Z}=0.7$

\subsubsection{Gumbel Max probability distribution function}

Gumbel Max probability distribution function for the convective heat transfer coefficient is expressed as follows:

$$
\mathrm{f}(\mathrm{h})=\frac{1}{\sigma} \exp \left[-\left(\frac{\mathrm{h}-\mu}{\sigma}\right)-\exp \left(-\left(\frac{\mathrm{h}-\mu}{\sigma}\right)\right)\right]
$$

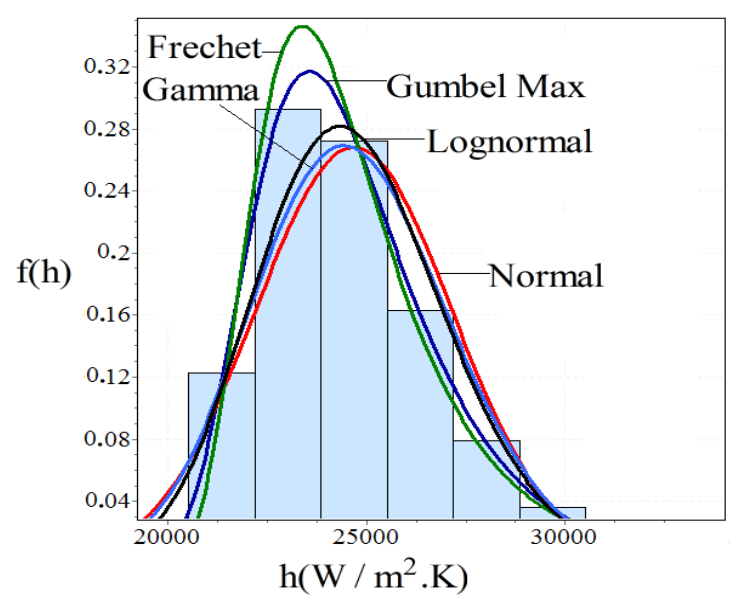

Figure 8: Appropriate probability distribution function of the convective heat transfer coefficient in $\mathrm{Z}=0.9$

Based on the above equation, $\mathrm{h}$ is the convective heat transfer coefficient and $\sigma, \mu$ are continuous scale parameter and continuous location parameter of Gumbel Max probability distribution function, respectively. In Figures (4) to (8) probability distribution functions of the convective heat transfer coefficient data for nanoparticles volume fraction in the range of 0 to 6 percent is drawn along five point of the tube (i.e. 0.04, 0.1, 0.4, 0.7 and 0.9).

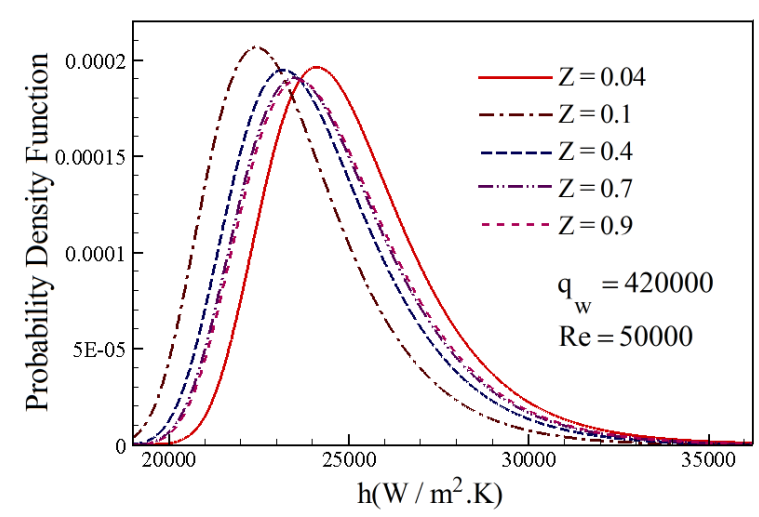

Figure 9: Comparing the Gumbel Max probability distribution function for convective heat transfer coefficient in different parts of the tube

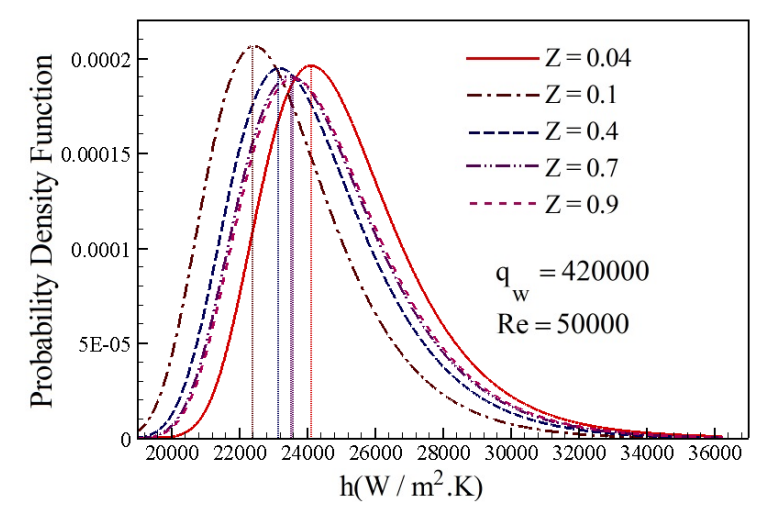

Figure 10: Comparing the Gumbel Max probability distribution function for convective heat transfer coefficient in different parts of the tube and show it's mode.

As is clear from these figures, according to the chi-square test, the best of probability distribution function for the convective heat transfer coefficient in all location of tube length is obtained the Gumbel Max probability distribution function. For this purpose, parameters of this probability distribution function are given in Table 2. The values of $\sigma$ and $\mu$ are calculated in parts of the developed and developing region of flow. Based on the results in Table 2, as seen, the range from 0.04 to 0.7 of tube length, continuous scale parameter $(\sigma)$ of the probability distribution function is shown changes significantly. But, there is not shown significant changes in the range from 0.7 to 0.9 of tube length. According to the Figures (2) and (3), it is shown that with increasing volume fraction of nanoparticles, the amount of development is pulled to the end of the tube that the amount of Table 2 also, states this issue. 
Table.2. continuous scale and continuous location parameters of the probability distribution function for the convective heat transfer coefficient

\begin{tabular}{cccccc}
\hline $\begin{array}{c}\text { Location of tube } \\
(\text { meter })\end{array}$ & 0.04 & 0.1 & 0.4 & 0.7 & 0.9 \\
\hline$\sigma$ & 1876.526 & 1778.1 & 1885.3 & 1926.6 & 1938.3 \\
& & 59 & 95 & 8 & 97 \\
$\mu$ & 24118.78 & 22409. & 23160. & 23470. & 23558. \\
& 4 & 493 & 758 & 418 & 055 \\
\hline
\end{tabular}

According to the results from in Table 3, the Gumbel Max probability density function for the turbulent forced convection heat transfer coefficient in different parts of the tube length is shown in Figure 9. As in Figures (2) and (3) is observed, the amount of the convective heat transfer coefficient at the beginning of the tube, in developing region is high. Then is reduced to a minimum and again increased. Finally in developed region will reach to a fixed amount. This issue also is observed in Figures (9) and (10). As is clear, by increasing the length of tube, the mode of probability distribution function is shown changes significantly in the range from 0 to 0.7 of tube length and then remains constant in the range from 0.7 to 0.9 of tube length. Based on the Figure 10, the amount of convective heat transfer coefficient in this area is result about $23500\left(\mathrm{w} / \mathrm{m}^{2} \cdot \mathrm{k}\right)$.Therefore, it can be concluded that for changes in volume fraction of the nanoparticles in the range of 0 to 6 percent, the mode of Gumbel Max distribution for the convective heat transfer coefficient is obtained about $23500\left(\mathrm{w} / \mathrm{m}^{2} \cdot \mathrm{k}\right)$.

The maximum difference between the mode value of the probability density functions is observed in interval of the undeveloped region (range of 0.04 to 0.1 ). But, the difference between the mode density functions for developed flow (range of 0.7 to 0.9 ) is not considerable. Also, based on the Figure 9 and 10 it is clear that skewness of this functions are tended to the right that is agreement with the results of Table 1.

\section{Conclusion}

In this paper, the statistical analysis of the effect of nanoparticles volume fraction on turbulent forced convective heat transfer coefficient is investigated in a circular tube with water- $\mathrm{Al}_{2} \mathrm{O}_{3}$ nanofluid. Uniform heat flux at the top and insulation at the bottom of the tube are assumed. In the studied tube flow, the heat transfer parameters are numerically evaluated based on various volume fraction of nanoparticles in the range of 0 to $6 \%$ with a constant value of the nanoparticle diameter (i.e. $\mathrm{d}_{\mathrm{p}}=36 \mathrm{~nm}$ ) and Reynolds number of $5 \times 10^{4}$. The summary of statistical results which are obtained based on numerical simulation of the flow tube for heat transfer parameters, are summarized as

1. The parameters of the probability distribution functions are shown insignificant Changes for the heat transfer coefficient in the range of 0.7 to 0.9 tube length.

2. The mode of probability distribution for the heat transfer coefficient is extracted about $23500\left(\mathrm{w} / \mathrm{m}^{2} . \mathrm{k}\right)$ based on the volume fraction of nanoparticles in the range of 0 to $6 \%$.

3. The convective heat transfer coefficient with respect to increase the volume fraction of nanoparticles is increased. The extreme value probability distribution function can be applied to define the probabilistic characteristics of the heat transfer turbulent nanofluid. Therefore, the Gumbel Max probability density functions can be used for convective heat transfer coefficient.

4. The convective heat transfer coefficient data is followed with Gumbel Max distribution function which is tended to the right.

5. Statistical results of development flow are not significant different but, the mode of heat transfer parameters are shown significant changes in the undeveloped region. 


\section{References}

Choi, S.U.S., (1995). Enhancing thermal conductivity of fluid with nanoparticles Developments and Applications of NonNewtonian flows. D.A. Siginer and H.P. Wangeds., FED, 66, pp. 99-105.

Rabienataj Darzi, A.A., Farhadi, M., and Sedighi, K., (2013). Heat transfer and flow characteristics of $\mathrm{AL}_{2} \mathrm{O}_{3}$-water nanofluid in a double tube heat exchanger. International Communications in Heat and Mass Transfer, 47, pp. 105-112.

Mirmasoumi, S. and Behzadmehr, A., (2008). Numerical study of laminar mixed convection of a nanofluid in a horizontal tube using twophase mixture model. Applied Thermal Engineering, 28, pp. 717-727.

Ben Mansour, R., Galanis, N. and Nguyen, C.T., (2011). Experimental study of mixed convection with watere $\mathrm{Al} 2 \mathrm{O} 3$ nanofluid in inclined tube with uniform wall heat flux. International Journal of Thermal Sciences, 50, pp. 403-410.

Vajjha, R. S., Das, D. K. and Ray, D. R., (2015). Development of new correlations for the Nusselt number and the friction factor under turbulent flow of nanofluids in flat tubes. International Journal of Heat and Mass Transfer, 80, pp. 353-367.

Minea, A. A., (2013). Effect of microtube length on heat transfer enhancement of an water/A12O3 nanofluid at high Reynolds numbers. International Journal of Heat and Mass Transfer, 62, pp. 22-30.

Farajollahi, B., Etemad, S.Gh. and Hojjat, M., (2010). Heat transfer of nanofluids in a shell and tube heat exchanger. International Journal of Heat and Mass Transfer, 53, pp. 12-17.

Dawood, H.K., Mohammed, H.A. and Munisamy, K.M., (2014). Heat transfer augmentation using nanofluids in an elliptic annulus with constant heat flux boundary condition. Case Studiesin Thermal Engineering, 4, pp.32-41.
Saha, G. and Paul, M. C., (2015). Heat transfer and entropy generation of turbulent forced convection flow of nanofluids in a heated pipe. International Communications in Heat and Mass Transfer, 61, pp. 26-36.

Kaminski, M. and Ossowski, R. L., (2014). Prediction of the effective parameters of the nanofluids using the generalized stochastic perturbation method. Physica A, 393, pp. 1022.

O.R. Seryasat, M.A. Shoorehdeli, M. Ghane, J. Haddadnia, M. Zeinali; Intelligent Fault Detection of Ball bearing Using FFT, STFT Energy Entropy and RMS, Life Science Journal 9 (3), pp 1781-1786.

Bianco, V., Manca, O. and Nardini, S., (2014). Performance analysis of turbulent convection heat transfer of $\mathrm{Al} 2 \mathrm{O} 3$ water-nanofluid in circular tubes at constant wall temperature. Energy, 31, pp.1-11.

Khanafer, K. and Vafai, K., (2011). A critical synthesis of thermophysical characteristics of nanofluids. International Journal of Heat and Mass Transfer, 54, pp. 4410-4428.

Corcione, M. , (2012). A Semi-Empirical Model for Predicting the Effective, Dynamic Viscosity of Nanoparticle Suspensions, Heat Transfer Engineering. 33(7), pp.575-583.

Kamyar, A., Saidur, R. and Hasanuzzaman, M., (2012). Application of Computational Fluid Dynamics (CFD) for nanofluids. International Journal of Heat and Mass Transfer, 55, pp. 4104-4115.

Tahir, S. and Mital, M., (2012). Numerical investigation of laminar nanofluid developing flow and heat transfer in a circular channel. Applied Thermal Engineering, 39, pp. 8-14.

Bianco, V., Manca, O. and Nardini, S., (2011). Numerical investigation on nanofluids turbulent convection heat transfer inside a circular tube. International Journal of Thermal Sciences, 50, pp. 341-349.

Akbarinia, A. and Laur, R., (2009). Investigating the diameter of solid particles effects on a laminar nanofluid flow in a curved tube using a two phase approach. International 
Journal of Heat and Fluid Flow, 30, pp. 706714.

Manninen, M., Taivassalo, V. and Kallio, S., (1996). On the Mixture Model for Multiphase Flow. Technical Research Center of Finland, 288, pp. 9-18.

Schiller, L. and Naumann, A., (1935). A drag coefficient correlation. Z. Ver. Deutsch. Ing, 77, pp. 318-320.

Launder, B.E. and Spalding, D.B., (1972). Lectures in Mathematical Models of Turbulence. Academic Press, London, England.

Khanafer, K. and Vafai, K., (2011). A critical synthesis of thermophysical characteristics of nanofluids. International Journal of Heat and Mass Transfer, 54, pp. 4410- 4428.

Chon, C.H., Kihm, K.D., Lee, S. P., and Choi, S.U.S., (2005). Empirical correlation finding the role of temperature and particle size for nanofluid (Al2O3) thermal conductivity enhancement. Applied Physics Letters, 87, pp. 1-3.

Masoumi, N., Sohrabi, N., and Behzadmehr, A., (2009). A new model for calculating the effective viscosity of nanofluids. Journal of Physics D: Applied Physics, 42, pp. 1-6.

Gulikers, J., and Raupach, M., (2006). Preface. Modelling of reinforcement corrosion in concrete. Materials and Corrosion, 57(8) , pp 603-604.

Gupta, S. P., (1997), Statistical Method. New Delhi.

Rohatgi, V. K. and, Ehsanes, S. A. K., (2001). Introduction to probability and statistics. Macmillan published Company, New York. 